\title{
Evaporation modeling to predict feasibility of life in hyper-saline brines
}

\author{
SARA M. SMITH* AND SIMON R. POULSON
}

Dept. Geological Sci. \& Eng. MS-172, University of Nevada, Reno, NV 89557, USA (* saramsmith@nevada.unr.edu, poulson@unr.edu)

Investigating how evaporation affects the characteristics of water is necessary to improve understanding of potential habitability in hyperarid environments on Earth, and possibly on other planets such as Mars. We modeled the effect of evaporation on important characteristics of water that allow microbial life to form, such as an activity of water $\left(a_{w}\right)$ higher than 0.61 [1], the activity of specific ions $\left(\mathrm{a}_{\mathrm{i}}\right)$, and salt precipitation parageneses, in order to help us determine the ionic limits of life in these extreme environments. Chaotropic vs. kosmotropic effects of specific aqueous ions were also considered. Modeling of evaporation trajectories for water chemistries from a Badwater Basin brine pool (BW1) and from a nearby spring (DV-40) [2], both in Death Valley USA, was performed with Geochemist's Workbench using Pitzer parameters. Evaporation calculations were performed at $25^{\circ} \mathrm{C}$, with concentration factors up to $1000 \mathrm{X}$.

Both waters become hyper-saline, with final ionic strength (I) $>10 \mathrm{~mol} / \mathrm{L}$. Values of $\mathrm{a}_{\mathrm{w}}$ for DV-40 remain above 0.7 , while $\mathrm{a}_{\mathrm{w}}$ of BW1 falls below 0.61 when I surpasses 11 $\mathrm{mol} / \mathrm{L}$. The initial concentration ratios of specific ions in the initial water chemistries resulted in different evaporation pathways and final water compositions. The precipitation paragenesis for DV-40 was dominated by halite and various $\mathrm{K}-\mathrm{Ca}-\mathrm{Mg}$ sulfates, while BW1 precipitation was dominated by halite and anhydrite. For evaporation of DV-40, $a_{i}$ of the kosmotropic ions $\mathrm{Na}^{+}$and $\mathrm{Cl}^{-}$increase, likely counteracting the increase in $\mathrm{a}_{\mathrm{i}}$ of the chaotropic cation $\mathrm{Mg}^{2+}$. For evaporation of $\mathrm{BW} 1, \mathrm{a}_{i}$ of the kosmotropic ion $\mathrm{Cl}^{-}$increases, while $\mathrm{a}_{\mathrm{i}}$ of the kosmotropic ions $\mathrm{SO}_{4}{ }^{2-}, \mathrm{Na}^{+}$and $\mathrm{K}^{+}$decrease, and ai of the chaotropic ions $\mathrm{Mg}^{2+}$ and $\mathrm{Ca}^{2+}$ increase.

The sustained values of $a_{w}>0.61$ to hyper-saline conditions suggests that microbes could continue to survive exceptionally high extents of evaporation, although specific kosmotropic vs. chaotropic interactions will also impact potential microbial activity. Continued modeling efforts will investigate the effect of variable starting water compositions, temperature and partial pressure of $\mathrm{CO}_{2}$ upon evaporation trajectories.

[1] Stevenson et al. (2015) Environ. Microbiol. 17, 257-277

[2] Li et al. (1997) BGSA 109, 1361-1371 